ORIGINAL

\title{
Impact of a multidisciplinary rehabilitation nutrition team on evaluating sarcopenia, cachexia and practice of rehabilitation nutrition
}

\author{
Yoji Kokura, RD ${ }^{1}$; Hidetaka Wakabayashi, MD, $\mathrm{PhD}^{2}$; Keisuke Maeda, MD, $\mathrm{PhD}^{3}$; Shinta Nishioka, $\mathrm{RD}^{4}$; \\ and Saori Nakahara, $\mathrm{RD}^{5}$.
}

\begin{abstract}
${ }^{1}$ Department of Clinical Nutrition, Keiju Medical Center, 94 Tomioka-chou, Nanao city, Ishikawa 926-8605, Japan, ${ }^{2}$ Department of Rehabilitation Medicine, Yokohama City University Medical Center, 4-57 Urafune-chou, Minami ward, Yokohama city, Kanagawa 232-0024, Japan, ${ }^{3}$ Department of Nutrition and Dysphagia Rehabilitation, Tamana Regional Health Medical Center, 2172 Tamana, Tamana city, Kumamoto 865-0005, Japan, ${ }^{4}$ Department of Clinical Nutrition and Food Services, Nagasaki Rehabilitation Hospital, 4-11 Gin-ya machi, Nagasaki city, Nagasaki 850-0854, Japan, ${ }^{5}$ Department of Nutrition, Suzuka General Hospital, 1275-53 Yamanohana, Yasuduka-chou, Suzuka city, Mie 513-8630, Japan
\end{abstract}

\begin{abstract}
Background/Aims : To determine whether the presence of a multidisciplinary rehabilitation nutrition team affects sarcopenia and cachexia evaluation and practice of rehabilitation nutrition. Methods : A cross-sectional study using online questionnaire among members of the Japanese Association of Rehabilitation Nutrition (JARN) was conducted. Questions were related to sarcopenia and cachexia evaluation and practice of rehabilitation nutrition. Results : 677 (14.7\%) questionnaires were analysed. $44.5 \%$ reported that their institution employed a rehabilitation nutrition team, $20.2 \%$ conducted rehabilitation nutrition rounds and $26.1 \%$ conducted rehabilitation nutrition meetings. A total of 51.7\%, 69.7\%, 69.0\% and 17.8\% measured muscle mass, muscle strength, physical function and cachexia, respectively. For those with a rehabilitation nutrition team, $63.5 \%, 80.7 \%, 82.4 \%$ and $22.9 \%$ measured muscle mass, muscle strength, physical function and cachexia, respectively, whereas $46.7 \%$, 78.0\% and $78.1 \%$ of the respondents reported implementation of nutrition planning strategies in consideration of energy accumulation, rehabilitation training in consideration of nutritional status and use of dietary supplements, respectively. Multivariate logistic regression analysis showed that the use of a rehabilitation nutrition team independently affected sarcopenia evaluation and practice of rehabilitation nutrition but not cachexia evaluation. Conclusions : The presence of a multidisciplinary rehabilitation nutrition team increased the frequency of sarcopenia evaluation and practice of rehabilitation nutrition. J. Med. Invest. 64 : 140 - 145, February, 2017
\end{abstract}

Keywords : Cachexia, Multidisciplinary team, Questionnaire, Rehabilitation nutrition, Sarcopenia

\section{INTRODUCTION}

The high prevalence of malnutrition, sarcopenia and cachexia among people with disabilities remains a global problem. The prevalence of protein energy malnutrition in hospitalized older patients is reported to range between $30 \%$ and $90 \%$, and $50.5 \%$ of patients in rehabilitation facilities, the highest proportion among all settings (1-3). Meanwhile, the prevalence of sarcopenia is $8-50 \%$ in persons aged $>60$ years (4-6) and that of cachexia is $5-15 \%$ in those with end-stage chronic heart failure and $50-80 \%$ in those with advanced cancer (7). The overall prevalence of cachexia is approximately $1 \%$ of the patient population, affecting an estimated 9 million people worldwide (7). Moreover, sarcopenia is often accompanied with malnutrition (8) ; it is estimated to affect over 50 million people worldwide, and this number is expected to increase to more than 2 billion in the next 40 years (9). Therefore, countermeasures to prevent sarcopenia and cachexia are very important.

Rehabilitation nutrition is a combination of both rehabilitation and nutrition care management that exert maximal function, activities and participation of persons with disabilities (10). Intervention with rehabilitation nutrition can improve activities of daily living,

Received for publication September 27, 2016; accepted February 1, 2017.

Address correspondence and reprint requests to Yoji Kokura, Registered dietitian. Department of Clinical Nutrition, Keiju Medical Center, 94 Tomioka chou, Nanao city, Ishikawa 926-8605, Japan and Fax :+810767-52-3218. muscle mass and strength, sarcopenic dysphagia and cachexia (11-15). Implementation of nutrition planning in consideration of energy accumulation, rehabilitation training with emphasis on nutritional status and use of dietary supplements can help alleviate malnutrition, sarcopenia and cachexia in persons with disabilities.

A multidisciplinary rehabilitation nutrition team may be effective to evaluate sarcopenia and cachexia. The diagnosis of sarcopenia relies on three indicators : muscle mass, muscle strength and physical performance (9). Assessment of the prevalence and causes of sarcopenia in persons with disabilities is also important in rehabilitation nutrition because the practice of rehabilitation nutrition depends on the aetiology of sarcopenia (1). The use of a multidisciplinary team could decrease the incidence of inappropriate drug use, shorten the length of hospitalisation and reduce total medical costs (16) and mortality (17). However, it remains unclear whether the presence of a multidisciplinary rehabilitation nutrition team affects the frequency of sarcopenia and cachexia evaluation and the practice of rehabilitation nutrition. Hence, further studies to assess knowledge of sarcopenia and cachexia among members of the interdisciplinary team in addition to dietitians are required (18).

The purpose of this study was to determine whether the presence of a multidisciplinary rehabilitation nutrition team affects the frequency of sarcopenia and cachexia evaluation and practice of rehabilitation nutrition. 


\section{METHODS}

\section{Participants}

The study participants were members of the Japanese Association of Rehabilitation Nutrition (JARN), which was established in 2011 (10) and includes 4621 members. The JARN established a Facebook group to encourage communication among members. Inclusion criteria were consent to participate in this study and response to the questionnaire. Responses to the questionnaires were excluded if data were missing or included a duplicative answer.

\section{Questionnaire period and methods}

The survey period was 2 weeks, November 8 to 22,2015 . The questionnaire was distributed using the Facebook group of the JARN, which included a description of the purpose and contents of the questionnaire survey. The survey was conducted online. Verification of the validity of questions and readability were determined by conducting pre-tests. Question items (Table 1) were related to the frequency of sarcopenia and cachexia evaluation and the practice of rehabilitation nutrition assessment.

\section{Formation of a team to implement rehabilitation nutrition}

Rehabilitation nutrition is similar to sports nutrition in that it consists of both rehabilitation and nutrition care management. This concept was devised by the International Classification of Functioning, Disability and Health (ICF) to assess nutritional status to maximise functionality of persons with disabilities (10). Rehabilitation nutrition team is a kind of nutrition support team. In addition to the normal nutritional support, this emphasizes on nutritional management and takes into account life function and rehabilitation program (rehabilitation as seen from nutrition management) and rehabilitation training with emphasis on nutritional status, nutritional intake and nutrition management (nutrition management as seen from rehabilitation). In addition, this team encourages the intake of oral nutritional supplements with high-branched-chain amino acids immediately after rehabilitation training and implements nutrition support, which is a combination of both rehabilitation and nutrition care management. Furthermore, rehabilitation nutrition team proposes an attending physician for the rehabilitation nutrition care plan. The criteria were evaluated by a rehabilitation nutrition team during rehabilitation nutrition rounds and rehabilitation nutrition meetings. The following seven items were comprehensively assessed to meet the standards of the ICF : (1) Evaluation of current nutritional status management strategies ; (2) Evaluation of each item in the ICF ; (3) Current training content of rehabilitation programs ; (4) Prognosis of nutritional status and goal setting ; (5) Prognosis of rehabilitation goals and goal setting ; (6) Nutrition management plan in consideration of rehabilitation training ; (7) Rehabilitation plan in consideration of nutritional status. The rehabilitation nutrition team discusses strategies to implement items (1) to (7). The rehabilitation nutrition round refers to bedside visits by the rehabilitation nutrition team. Rehabilitation nutrition meetings refer to conversations or exchanges of information about functional evaluation, prognosis and rehabilitation training content between disciplines.

\section{Evaluation of cachexia}

Evaluation method of cachexia was investigated about the guidelines of the European Palliative Care Research Collaborative (19, 20) or definition of the Washington consensus meeting (21). Diagnostic criteria for cachexia of European Palliative Care Research Collaborative was weight loss greater than $5 \%$, or weight loss greater than $2 \%$ in individuals already showing depletion according to current bodyweight and height (body-mass index [BMI] $<20 \mathrm{~kg} / \mathrm{m}$ (2)) or the loss of skeletal muscle mass (sarcopenia) $(19,20)$. Diagnostic criteria for cachexia by the definition of the Washington consensus meeting were weight loss of at least $5 \%$ in 12 months or less in the presence of underlying illness, plus any three of the following criteria : decreased muscle strength fatigue, anorexia, low fat-free mass index, abnormal biochemistry (21).

\section{Data Analysis}

A sample size of more than 664 persons, under assumptions of two-choice question, and $50 \%$ selection with a $5 \%$ error based on $99 \%$ reliability were found to be necessary. Categorical data are expressed as percentages, and differences were analysed using the Chi-square test. Multivariate logistic regression analysis was performed to identify the variables that were independently associated with each outcome (measure of muscle mass, muscle strength and physical function, evaluation of cachexia and activities of daily living, the implementation of nutrition planning in consideration of the degree of activity and the implementation of nutrition planning in consideration of energy accumulation, rehabilitation training with emphasis on nutritional status and use of dietary supplements). Factors with a low incidence were excluded from multivariate logistic regression analysis and were described 'not available'. Variance inflation factors (VIFs) were used to evaluate multicollinearity for each model. We considered a VIF value of $>2$ as demonstrating multicollinearity. In all cases, a $p$ value of $<0.05$ was considered statistically significant. All statistical analyses were performed using EZR (22) software ver. 1.31, which was developed from the open-source statistical software R (23).

\section{Ethical considerations}

Informed consent was obtained from all participants. The questionnaires were completed anonymously to protect personal information and guaranteed confidentiality to the respondents. The study protocol was approved by the ethics committee of Suzuka General Hospital (Suzuka, Japan) and conducted in accordance with the tenets of the 1964 Declaration of Helsinki and its later amendments.

\section{RESULTS}

Of a total of 716 completed questionnaire that were received, 39 (5.4\%) were excluded from analysis due to anomalies in the responses (19 completed questionnaires filled by respondents working at a clinic, pharmacy, or dental clinic were excluded because of the little relationship to team activity, 13 questionnaires had duplication, 6 had missing values and 1 contained obvious inconsequential responses to key questions). Consequently, 677 questionnaires were included for analysis (14.7\% response rate).

As shown in Table 1, affiliation of the respondents included acute general wards (303, 44.7\%), convalescent rehabilitation wards $(176,26.0 \%)$, medical care or long-term care facilities $(50,7.4 \%)$, long-term care health facilities (51, 7.5\%), homecare services (44, $6.5 \%)$, other hospitals $(29,4.3 \%)$, educational institutions $(7,1.0 \%)$, regional comprehensive care wards $(3,0.5 \%)$, day services, visiting nursing and outpatient rehabilitation $(6,0.9 \%)$ and others $(8,1.2 \%)$. The median length of work experience was 11 (interquartile range, $7-18$ ) years. Of all respondents, $44.5 \%$ employed rehabilitation nutrition teams, $20.2 \%$ employed rehabilitation nutrition rounds and $26.1 \%$ conducted rehabilitation nutrition meetings. Of the respondents, $51.7 \%, 69.7 \%, 69.0 \%, 86.1 \%$ and $17.8 \%$ reported that muscle mass, muscle strength, physical function, activities of daily living and cachexia, respectively, were regularly measured. A total of $59(48.7 \%)$ and $44(36.3 \%)$ respondents, respectively, reported that the methods for evaluation of cachexia were based on the European Palliative Care Research Collaborative guidelines or the Washington consensus meeting. Also, $46.7 \%, 78.0 \%$ and $78.1 \%$ of the respondents reported implementation of nutrition planning in 
Table 1. Questionnaire and sample characteristics

\begin{tabular}{|c|c|c|}
\hline \multicolumn{3}{|l|}{ 1. What is your occupation? } \\
\hline Total, n (\%) & \multicolumn{2}{|l|}{$677(100)$} \\
\hline Medical doctor, n (\%) & \multicolumn{2}{|l|}{$40(5.9)$} \\
\hline Dentist, n (\%) & \multicolumn{2}{|l|}{$17(2.5)$} \\
\hline Nurse, n (\%) & \multicolumn{2}{|l|}{$56(8.3)$} \\
\hline Pharmacist, n (\%) & \multicolumn{2}{|l|}{$10(1.5)$} \\
\hline Registered dietitian, n (\%) & \multicolumn{2}{|l|}{$178(26.3)$} \\
\hline Physical therapist, n (\%) & \multicolumn{2}{|l|}{$193(28.5)$} \\
\hline Occupational therapist, n (\%) & \multicolumn{2}{|l|}{$40(5.9)$} \\
\hline Speech therapist, n (\%) & $112(16.5)$ & \\
\hline Dental hygienist, $\mathrm{n}(\%)$ & $22(3.3)$ & \\
\hline Others, n (\%) & $9(1.3)$ & \\
\hline 2. What is your affiliation? & & \\
\hline Acute general ward, n (\%) & $303(44.7)$ & \\
\hline Convalescent rehabilitation ward, n (\%) & $176(26.0)$ & \\
\hline Medical care or long-term care ward, n (\%) & $50(7.4)$ & \\
\hline Long-term care health facility, n (\%) & $51(7.5)$ & \\
\hline Homecare service, $\mathrm{n}(\%)$ & $44(6.5)$ & \\
\hline Other hospital, n (\%) & $29(4.3)$ & \\
\hline Educational institution, $\mathrm{n}(\%)$ & $7(1.0)$ & \\
\hline Regional comprehensive care ward, n (\%) & $3(0.5)$ & \\
\hline Day service, Visiting nursing and Outpatient Rehabilitation, n (\%) & $6(0.9)$ & \\
\hline Others, $\mathrm{n}(\%)$ & $8(1.2)$ & \\
\hline 3. How many years of work experience? & & \\
\hline Year (s), median $(25 \%-75 \%)$ & $11(7-18)$ & \\
\hline 4. Is there a rehabilitation nutrition team in your facility? & & \\
\hline Yes, n (\%) & $301(44.5)$ & \\
\hline No, n (\%) & $376(55.5)$ & \\
\hline & Yes & No \\
\hline Medical doctor, n (\%) & $25(8.3)$ & $15(4.0)$ \\
\hline Dentist, $\mathrm{n}(\%)$ & $8(2.7)$ & $9(2.4)$ \\
\hline Nurse, $\mathrm{n}(\%)$ & $24(8.0)$ & $32(8.5)$ \\
\hline Pharmacist, n (\%) & $3(1.0)$ & $7(1.9)$ \\
\hline Registered dietitian, n (\%) & $68(22.6)$ & $110(29.3)$ \\
\hline Physical therapist, n (\%) & $102(33.9)$ & $91(24.2)$ \\
\hline Occupational therapist, $\mathrm{n}(\%)$ & $17(5.7)$ & $23(6.1)$ \\
\hline Speech therapist, $\mathrm{n}(\%)$ & $44(14.6)$ & $68(18.1)$ \\
\hline Dental hygienist, n (\%) & $9(2.9)$ & $13(3.5)$ \\
\hline Others, n (\%) & $1(0.3)$ & $8(2.1)$ \\
\hline 5. Are rehabilitation nutrition rounds conducted in your facility? & & \\
\hline Yes, n (\%) & $137(20.2)$ & \\
\hline No, n (\%) & $540(79.8)$ & \\
\hline 6. Are rehabilitation nutrition meetings conducted in your facility? & & \\
\hline Yes, n (\%) & $177(26.1)$ & \\
\hline No, n (\%) & $500(73.9)$ & \\
\hline 7. Do you measure muscle mass? & & \\
\hline Yes, n (\%) & $350(51.7)$ & \\
\hline No, n (\%) & $327(48.3)$ & \\
\hline 8. Do you measure muscle strength? & & \\
\hline Yes, n (\%) & $472(69.7)$ & \\
\hline No, n (\%) & $205(30.3)$ & \\
\hline 9. Do you measure physical function? & & \\
\hline Yes, n (\%) & $467(69.0)$ & \\
\hline No, n (\%) & $210(31.0)$ & \\
\hline 10. Do you measure activities of daily living? & & \\
\hline Yes, n (\%) & $589(86.1)$ & \\
\hline No, n (\%) & $94(13.9)$ & \\
\hline 11. Do you evaluate cachexia? & & \\
\hline Yes, n (\%) & $121(17.8)$ & \\
\hline No, n (\%) & $556(82.2)$ & \\
\hline 12. How do you evaluate cachexia? & & \\
\hline EPCRC guidelines, $\mathrm{n}(\%)$ & $59(48.7)$ & \\
\hline Definition of the Washington consensus meeting, $\mathrm{n}(\%)$ & $44(36.3)$ & \\
\hline 13. Do you implement nutrition planning in consideration of activity & & \\
\hline Yes, n (\%) & $345(51.0)$ & \\
\hline No, n (\%) & $332(49.0)$ & \\
\hline 14. Do you implement nutrition planning in consideration of energy & & \\
\hline Yes, n (\%) & $316(46.7)$ & \\
\hline No, n (\%) & $361(53.3)$ & \\
\hline 15. Do you implement rehabilitation training with emphasis on nutr & & \\
\hline Yes, n (\%) & $528(78.0)$ & \\
\hline No, n (\%) & $149(22.0)$ & \\
\hline 16. Do you use dietary supplements? & & \\
\hline Yes, n (\%) & $529(78.1)$ & \\
\hline No, n (\%) & $148(21.9)$ & \\
\hline 17. Have you participated in a congress or seminar of the JARN? & & \\
\hline Yes, n (\%) & $506(74.7)$ & \\
\hline No, $n(\%)$ & $171(25.3)$ & \\
\hline
\end{tabular}

Abbreviations : EPCRC, European Palliative Care Research Collaborative ; JARN, Japanese Association of Rehabilitation Nutrition 
consideration of energy accumulation, rehabilitation training with emphasis on nutritional status and use of dietary supplements, respectively.

Table 2 shows the results of the univariate analyses regarding the use of a team to implement rehabilitation nutrition programs. As described, $63.5 \%, 80.7 \%, 82.4 \%, 22.9 \%$ and $93.0 \%$ of the rehabilitation nutrition teams measured muscle mass, muscle strength and physical function and evaluated cachexia and activities of daily living, respectively. Also, $64.7 \%, 89.0 \%$ and $89.4 \%$ of the rehabilitation nutrition teams reported nutrition planning in consideration of energy accumulation, rehabilitation training with emphasis on nutritional status and use of dietary supplements, respectively.

Table 3 shows the results of multivariate analyses of each outcome after adjusting for confounding factors, including affiliation, years of work experience, existence of rehabilitation nutrition team rounds and existence of rehabilitation nutrition team meetings and attendance of a congress or seminar of the JARN. The employment of a rehabilitation nutrition team affects the measurement of muscle mass and strength, measurement of physical function, evaluation of activities of daily living, nutrition planning in consideration of energy accumulation and rehabilitation training with emphasis on nutritional status and use of dietary supplements. However, there was no significant difference in the frequency of cachexia evaluation between facilities that did or did not employ a rehabilitation nutrition team. The VIFs did not demonstrate significant multicollinearity between any factors on multivariate analysis.

\section{DISCUSSION}

There were three important clinical findings of the present study. First, the presence of a multidisciplinary rehabilitation nutrition team was associated with a high frequency of implementing measures of muscle mass, muscle strength and physical performance for evaluation of sarcopenia. Second, the existence of rehabilitation nutrition team was not significantly associated with cachexia evaluation. Third, a high proportion of facilities having multidisciplinary rehabilitation nutrition teams implemented rehabilitation nutrition

Table 2. Univariate analysis of teams for implementation of rehabilitation nutrition programs

\begin{tabular}{|c|c|c|c|c|}
\hline \multirow[t]{2}{*}{ Characteristics } & \multirow[t]{2}{*}{ Implementation } & \multicolumn{2}{|c|}{ Presence of a rehabilitation nutrition team } & \multirow[t]{2}{*}{$p$-value } \\
\hline & & Yes & No & \\
\hline \multirow[t]{2}{*}{ Measurement of muscle mass } & Yes, n (\%) & $191(63.5)$ & $159(42.3)$ & $<0.001 \dagger$ \\
\hline & No, n (\%) & $110(36.5)$ & $217(57.7)$ & \\
\hline \multirow[t]{2}{*}{ Measure of muscle strength } & Yes, n (\%) & $243(80.7)$ & $229(60.9)$ & $<0.001 \dagger$ \\
\hline & No, n (\%) & $58(19.3)$ & $147(39.1)$ & \\
\hline \multirow[t]{2}{*}{ Measure of physical function } & Yes, n (\%) & $248(82.4)$ & $219(58.2)$ & $<0.001 \dagger$ \\
\hline & No, n (\%) & $53(17.6)$ & $157(41.8)$ & \\
\hline \multirow[t]{2}{*}{ Evaluation of cachexia } & Yes, n (\%) & $69(22.9)$ & $52(13.8)$ & $0.002 \dagger$ \\
\hline & No, n (\%) & $232(77.1)$ & $324(86.2)$ & \\
\hline \multirow[t]{2}{*}{ Evaluation of activities of daily living } & Yes, n (\%) & $280(93.0)$ & $303(80.6)$ & $<0.001 \dagger$ \\
\hline & No, n (\%) & $21(7.0)$ & $73(19.4)$ & \\
\hline \multirow{2}{*}{$\begin{array}{l}\text { Nutrition planning in consideration of energy } \\
\text { accumulation }\end{array}$} & Yes, n (\%) & $195(64.7)$ & $121(32.2)$ & $<0.001 \dagger$ \\
\hline & No, n (\%) & $106(35.3)$ & $255(67.8)$ & \\
\hline \multirow{2}{*}{$\begin{array}{l}\text { Rehabilitation training with emphasis on } \\
\text { nutritional status }\end{array}$} & Yes, n (\%) & $268(89.0)$ & $260(69.2)$ & $<0.001 \dagger$ \\
\hline & No, n (\%) & $33(11.0)$ & $116(30.8)$ & \\
\hline \multirow[t]{2}{*}{ Use of dietary supplements } & Yes, n (\%) & $269(89.4)$ & $260(69.2)$ & $<0.001 \dagger$ \\
\hline & No, n (\%) & $32(10.6)$ & $116(30.8)$ & \\
\hline
\end{tabular}

$\dagger$ Chi-square test

Table 3. Multivariate logistic regression analysis for each outcome

\begin{tabular}{|c|c|c|c|c|c|c|c|c|c|c|c|c|c|c|c|c|}
\hline \multirow[t]{2}{*}{ Factor } & \multicolumn{2}{|c|}{$\begin{array}{l}\text { Measure of } \\
\text { muscle mass }\end{array}$} & \multicolumn{2}{|c|}{$\begin{array}{l}\text { Measure of } \\
\text { muscle strength }\end{array}$} & \multicolumn{2}{|c|}{$\begin{array}{l}\text { Measure of } \\
\text { physical function }\end{array}$} & \multicolumn{2}{|c|}{$\begin{array}{l}\text { Evaluate of } \\
\text { cachexia }\end{array}$} & \multicolumn{2}{|c|}{$\begin{array}{l}\text { Evaluate of activities } \\
\text { of daily living }\end{array}$} & \multicolumn{2}{|c|}{$\begin{array}{l}\text { Nutrition planning } \\
\text { in consideration of } \\
\text { energy accumulation }\end{array}$} & \multicolumn{2}{|c|}{$\begin{array}{l}\text { Rehabilitation training } \\
\text { with emphasis on } \\
\text { nutritional status }\end{array}$} & \multicolumn{2}{|c|}{$\begin{array}{l}\text { Use of dietary } \\
\text { supplements }\end{array}$} \\
\hline & $\mathrm{R}, 95 \% \mathrm{CI}$ & $\mathrm{p}$-value & $0 \mathrm{R}, 95 \% \mathrm{CI}$ & $\mathrm{p}$-value & OR, $95 \% \mathrm{CI}$ & $\mathrm{p}$-value & OR, $95 \% \mathrm{CI}$ & $\mathrm{p}$-value & OR, $95 \% \mathrm{CI}$ & $\mathrm{p}$-value & OR, $95 \% \mathrm{CI}$ & $\mathrm{p}$-value & $0 \mathrm{R}, 95 \% \mathrm{CI}$ & $\mathrm{p}$-value & OR, $95 \% \mathrm{CI}$ & $\mathrm{p}$-value \\
\hline \multirow{2}{*}{$\begin{array}{l}\text { Rehabilitation nutrition } \\
\text { team in the facility }\end{array}$} & 1.95 & 0.001 & 2.29 & $<0.001$ & 3.12 & $<0.001$ & 1.30 & 0.33 & 2.93 & 0.002 & 3.64 & $<0.001$ & 2.78 & $<0.001$ & 2.69 & $<0.001$ \\
\hline & $1.31-2.90$ & & $1.45-3.60$ & & $1.95-5.00$ & & $0.77-2.18$ & & $1.48-5.80$ & & $2.40-5.54$ & & $1.64-4.71$ & & $1.57-4.58$ & \\
\hline \multirow{2}{*}{$\begin{array}{l}\text { Years of work } \\
\text { experience }\end{array}$} & 0.99 & 0.285 & 0.96 & $<0.001$ & 0.96 & $<0.001$ & 1.02 & 0.15 & 0.95 & 0.001 & 1.01 & 0.011 & 0.99 & 0.55 & 0.96 & 0.003 \\
\hline & $0.96-1.01$ & & $0.94-0.98$ & & $0.93-0.98$ & & $0.99-1.04$ & & $0.93-0.98$ & & $1.00-1.05$ & & $0.96-1.02$ & & $0.94-0.98$ & \\
\hline \multirow{2}{*}{$\begin{array}{l}\text { Rehabilitation nutrition } \\
\text { rounds in the facility }\end{array}$} & 0.98 & 0.934 & 1.24 & 0.477 & 1.36 & 0.32 & 0.77 & 0.36 & 0.82 & 0.66 & 0.45 & 0.004 & 1.27 & 0.533 & 1.21 & 0.629 \\
\hline & $0.59-1.61$ & & $0.68-2.26$ & & $0.73-2.52$ & & $0.43-1.36$ & & $0.34-1.99$ & & $0.26-0.77$ & & $0.59-2.69$ & & $0.56-2.57$ & \\
\hline \multirow{2}{*}{$\begin{array}{l}\text { Rehabilitation nutrition } \\
\text { meetings in the facility }\end{array}$} & 1.63 & 0.031 & 1.27 & 0.368 & 0.98 & 0.92 & 2.45 & 0.001 & 0.19 & 0.19 & 2.9 & $<0.001$ & 1.53 & 0.182 & 2.01 & 0.038 \\
\hline & $1.04-2.55$ & & $0.75-2.13$ & & $0.57-1.64$ & & $1.45-4.15$ & & $0.77-3.68$ & & $1.80-4.67$ & & $0.81-2.87$ & & $1.04-3.87$ & \\
\hline \multirow{2}{*}{$\begin{array}{l}\text { Participated in congress of } \\
\text { seminar of the JARN }\end{array}$} & 1.87 & 0.001 & 1.23 & 0.282 & 1.10 & 0.64 & 1.63 & 0.063 & 1.73 & 0.025 & 2.27 & $<0.001$ & 1.76 & 0.007 & 1.19 & 0.428 \\
\hline & $1.30-2.69$ & & $0.84-1.81$ & & $0.74-1.62$ & & $0.97-2.73$ & & $1.07-2.80$ & & $1.53-3.37$ & & $1.17-2.66$ & & 0.77-1.82 & \\
\hline
\end{tabular}

Abbreviations : 95\% CI, 95\% confidence interval ; JARN, Japanese Association of Rehabilitation Nutrition ; OR, odds ratio 
strategies.

The presence of a multidisciplinary rehabilitation nutrition team was related to a high proportion of institutes measuring muscle mass, muscle strength and physical performance for evaluation of sarcopenia. Previous studies have reported that $46-74 \%$ of institutes regularly evaluated sarcopenia $(18,24)$. In this study, 51.0$68.5 \%$ regularly evaluated sarcopenia. However, among institutes that employed a rehabilitation nutrition team, this rate increased to $63.6-82.5 \%$. The use of a multidisciplinary team could decrease the incidence of readmission to a critical care ward (25), lower the incidence of complications (26) and improve functional prognosis (27). Practice-based interprofessional collaboration interventions can lead to positive changes in health care management (16). The rehabilitation nutrition team exchanges information about functional evaluation, prognosis and content of rehabilitation training strategies. In addition, rehabilitation nutrition assessment includes the presence and cause of sarcopenia. Therefore, the use of a multidisciplinary rehabilitation nutrition team can increase the frequency of sarcopenia evaluation.

The presence of a rehabilitation nutrition team did not affect the frequency of cachexia evaluation. In older inpatients with hospitalassociated deconditioning, 88\% were malnourished and 30\% had precachexia, which was associated with poor rehabilitation outcomes (28). We evaluated pre-cachexia by the European Society for Clinical Nutrition and Metabolism consensus diagnostic criteria for pre-cachexia. Diagnostic criteria are (i) underlying chronic disease ; (ii) unintentional weight loss of less than $5 \%$ of usual body weight during the last 6 months ; (iii) chronic or recurrent systemic inflammatory response and (iv) anorexia or anorexia-related symptoms (29). Cachexia is more common in older patients and can adversely affect rehabilitation outcomes. Cachexia assessment is imperative in rehabilitation nutrition, although the rate of cachexia evaluation is low compared to that of sarcopenia evaluation. Previous studies reported that the range of cachexia recognition was $21-43 \%(18,24)$. In this study, implementation rate of cachexia evaluation by a rehabilitation nutrition team was $17.2 \%$. The low frequency of implementing cachexia evaluation may be due to the low frequency of cachexia recognition, no uniform criteria for diagnosis of cachexia and complicated diagnosis criteria that require several evaluation items (19-21). Therefore, it is important to develop uniform criteria for diagnosis of cachexia to increase the frequency of cachexia evaluation in clinical practice.

A high proportion of facilities having multidisciplinary rehabilitation nutrition teams regularly performed nutrition planning in consideration of energy accumulation, implemented rehabilitation training programs with emphasis on nutritional status and used dietary supplements. Originally, the rehabilitation nutrition team is different from nutrition support and rehabilitation teams in terms of considering energy accumulation, rehabilitation training with emphasis on nutritional status and intake dietary supplement after rehabilitation. It is rare for nutrition support team to measure muscle strength and physical function. Furthermore, it is meaningful to consider nutrition planning in consideration of energy accumulation, rehabilitation training with emphasis on nutritional status, and use of dietary supplements after rehabilitation by the rehabilitation nutrition team. The amount of accumulated energy is added to the daily energy expenditure to improve malnutrition and sarcopenia. Members of the rehabilitation nutrition team and registered dietitians set nutritional standards and determine energy accumulation, while rehabilitation therapists evaluate rehabilitation-related energy expenditure. The multidisciplinary rehabilitation nutrition team encourages weight increases to improve sarcopenia. Rehabilitation and training of a malnourished patient with poor nutritional intake can lead to weight loss, including lean body mass. The use of dietary supplements can significantly increase energy and protein intake (30). Therefore, rehabilitation nutrition may improve rehabilitation outcome in persons with disabilities and sarcopenia.

This study had a few limitations that should be addressed. First, there may have been overlaps by respondents from the same facility. However, evaluation of sarcopenia and cachexia and rehabilitation nutrition strategies can differ in the same facility. Second, the participants were limited to JARN members ; therefore, external validity is limited. Third, the questionnaire included only two questions for nutritional management. Fourth, the sample of respondents was heterogeneous, with only $5.9 \%$ being represented by physicians. It may have influenced the assessment rate of sarcopenia and cachexia. Fifth, we had not shown the effects of the rehabilitation nutrition team on sarcopenia, cachexia, nutritional status, and prognosis. Lastly, this research was based on a questionnaire survey conducted using the Internet. Therefore, the response rate of subjects was possibly different depending on age and other demographics, which affected the sample selection. In the future, we plan to investigate the evaluation of sarcopenia and cachexia and practice of rehabilitation nutrition by medical professions in different countries.

In conclusion, the presence of a multidisciplinary rehabilitation nutrition team was associated with an increased frequency of sarcopenia evaluation and practice of rehabilitation nutrition but not cachexia evaluation among members of the JARN. The frequency of cachexia evaluation was lower than that of sarcopenia. Further prospective studies are required to examine the effect of a rehabilitation nutrition team on improvement in evaluation of nutritional status, sarcopenia, cachexia, activities of daily living and quality of life.

\section{CONFLICTS OF INTEREST}

The authors declare that they have no conflict of interest.

\section{ACKNOWLEDGMENT}

The authors thank the JARN members for their valuable assistance with this project.

\section{REFERENCES}

1. Constans T, Bacq Y, Bréchot JF, Guilmot JL, Choutet P, Lamisse F : Protein-energy malnutrition in elderly medical patients. J Am Geriatr Soc 40 : 263-268, 1992

2. Pablo AM, Izaga MA, Alday LA : Assessment of nutritional status on hospital admission : nutritional scores. Eur J Clin Nutr 57 : 824-31, 2003

3. Kaiser MJ, Bauer JM, Rämsch C, Uter W, Guigoz Y, Cederholm T, Thomas DR, Anthony PS, Charlton KE, Maggio M, Tsai AC, Vellas B, Sieber CC : Frequency of malnutrition in older adults : a multinational perspective using the mini nutritional assessment. J Am Geriatr Soc 58 : 1734-38, 2010

4. Abellan van Kan $\mathrm{G}$ : Epidemiology and consequences of sarcopenia. J Nutr Health Aging 13 : 708-12, 2009

5. Alexandre Tda S, Duarte YA, Santos JL, Wong R, Lebrão ML: Prevalence and associated factors of sarcopenia among elderly in Brazil : findings from the SABE study. J Nutr Health Aging 18:284-90, 2014

6. Sánchez-Rodrígueza D, Calleb A, Contra A, Ronquillo N, Rodríguez-Marcos A, Vázquez-Ibar O, Colominasb M, Inzitarib M : Sarcopenia in post-acute care and rehabilitation of older adults : Sarcopenia in post-acute care and rehabilitation of older adults : A review. Eur Geriatr Med 7 : 224-231, 2016 
7. Von Haehling S, Anker SD : Prevalence, incidence and clinical impact of cachexia : facts and numbers-update 2014. J Cachexia Sarcopenia Muscle 5 : 253-259, 2014

8. Vandewoude MF, Alish CJ, Sauer AC, Hegazi RA : Malnutrition-sarcopenia syndrome $:$ is this the future of nutrition screening and assessment for older adults? J Aging Res 2012 : 651570, 2012

9. Cruz-Jentoft AJ, Baeyens JP, Bauer JM, Boirie Y, Cederholm T, Landi F, Martin FC, Michel JP, Rolland Y, Schneider SM, Topinková E, Vandewoude M, Zamboni M : Sarcopenia : European consensus on definition and diagnosis : Report of the European Working Group on Sarcopenia in Older People. Age Ageing 39 : 412-423, 2010

10. Wakabayashi H, Sakuma K : Rehabilitation nutrition for sarcopenia with disability : A combination of both rehabilitation and nutrition care management. J Cachexia Sarcopenia Muscle $5: 269-277,2014$

11. Yoshimura Y, Uchida K, Jeong S, Yamaga M : Effects of nutritional supplements on muscle mass and activities of daily living in elderly rehabilitation patients with decreased muscle mass : A randomized controlled trial. J Nutr Health Aging 20 : 185191, 2016

12. Hegerova P, Dedkova Z, Sobotka L : Early nutritional support and physiotherapy improved long-term self-sufficiency in acutely ill older patients. Nutrition 31 : 166-170, 2015

13. Maeda K, Akagi J : Treatment of sarcopenic dysphagia with rehabilitation and nutritional support : a comprehensive approach. J Acad Nutr Diet 116 : 573-577, 2016

14. Someya R, Wakabayashi H, Akiyama E, Hayashi K, Kimura K : Rehabilitation nutrition for acute heart failure on inotropes with malnutrition, sarcopenia, and cachexia : a case report. J Acad Nutr Diet 116 : 765-767, 2016

15. Wakabayashi H, Uwano R : Rehabilitation nutrition for possible sarcopenic dysphagia after lung cancer surgery : a case report. Am J Phys Med Rehabil 95 : 84-89, 2016

16. Zwarenstein M, Goldman J, Reeves S : Interprofessional collaboration : effects of practice-based interventions on professional practice and healthcare outcomes. Cochrane Database Syst Rev3 : CD000072, 2009

17. Deschodt M, Flamaing J, Haentjens P, Boonen S, Milisen K : Impact of geriatric consultation teams on clinical outcome in acute hospitals : a systematic review and meta-analysis. BMC Med $22: 48,2013$

18. Ter Beek L, Vanhauwaert E, Slinde F, Orrevall Y, Henriksen C, Johansson M, Vereecken C, Rothenberg E, Jager-Wittenaar $\mathrm{H}$ : Unsatisfactory knowledge and use of terminology regarding malnutrition, starvation, cachexia and sarcopenia among dietitians. Clin Nutr doi : 10.1016/j.clnu.2016.03.023, 2016

19. Radbruch L, Elsner F, Trottenberg P, Strasser F, Baracos V, Fearon K, editors : Clinical practice guidelines on cancer cachexia in advanced cancer patients. [monograph on the Internet]. Aachen, Department of Palliative Medicinen/European
Palliative Care Research Collaborative; Available from: http : / / www. epcrc. org / publication_listfiles. php ? id= mWdBCMI5eXVlcNFk7Gnq, 2011 [Cited 8 Aug 2016]

20. Fearon K, Strasser F, Anker SD, Bosaeus I, Bruera E, Fainsinger RL, Jatoi A, Loprinzi C, MacDonald N, Mantovani G, Davis M, Muscaritoli M, Ottery F, Radbruch L, Ravasco P, Walsh D, Wilcock A, Kaasa S, Baracos VE: Definition and classification of cancer cachexia : an international consensus. Lancet Oncol 12 : 489-495, 2011

21. Evans WJ, Morley JE, Argilés J, Bales C, Baracos V, Guttridge D, Jatoi A, Kalantar-Zadeh K, Lochs H, Mantovani G, Marks D, Mitch WE, Muscaritoli M, Najand A, Ponikowski P, Rossi Fanelli F, Schambelan M, Schols A, Schuster M, Thomas D, Wolfe R, Anker SD : Cachexia : a new definition. Clin Nutr 27 : 793-799, 2008

22. Kanda Y : Investigation of the freely available easy-to-use software 'EZR' for medical statistics. Bone Marrow Transplant $48: 452-458,2013$

23. Institute for Statistics and Mathematics of Wirtschaftsuniversität Wien : The Comprehensive R Archive Network [monograph on the Internet]. Available from : https : //cran.r-project.org/, 2016 [Cited 8 Aug 2016]

24. Yaxley A, Miller MD : The challenge of appropriate identification and treatment of starvation, sarcopenia, and cachexia : a survey of Australian dietitians. J Nutr Metab 2011 : 603161, 2011

25. Ball C, Kirkby M, Williams S : Effect of the critical care outreach team on patient survival to discharge from hospital and readmission to critical care : non-randomised population based study. BMJ 327 : 1014, 2003

26. Nehme AE : Nutritional support of the hospitalized patient. The team concept. JAMA $243: 1906-1908,1980$

27. Strasser DC, Falconer JA, Stevens AB, Uomoto JM, Herrin J, Bowen SE, Burridge AB : Team training and stroke rehabilitation outcomes : a cluster randomized trial. Arch Phys Med Rehabil $89: 10-15,2008$

28. Wakabayashi $\mathrm{H}$, Sashika $\mathrm{H}$ : Malnutrition is associated with poor rehabilitation outcome in elderly inpatients with hospitalassociated deconditioning a prospective cohort study. J Rehabil Med $46: 277-282,2014$

29. Muscaritoli M, Anker SD, Argilés J, Aversa Z, Bauer JM, Biolo G, Boirie Y, Bosaeus I, Cederholm T, Costelli P, Fearon KC, Laviano A, Maggio M, Rossi Fanelli F, Schneider SM, Schols A, Sieber CC : Consensus definition of sarcopenia, cachexia and precachexia : joint document elaborated by Special Interest Groups (SIG) "cachexia-anorexia in chronic wasting diseases" and "nutritionin geriatrics". Clin Nutr 29 : 154159, 2010

30. Collins J, Porter J : The effect of interventions to prevent and treat malnutrition in patients admitted for rehabilitation : a systematic review with meta-analysis. J Hum Nutr Diet 28 : 115,2015 